\title{
Effect of Weight Changes on the Development of Erosive Esophagitis
}

\author{
Tae-Heum Chung ${ }^{1 * *}$, Jiho Lee², In-Du Jeong ${ }^{3}$, Kun-Chul Lee ${ }^{4}$ \\ 'Department of Family medicine, Ulsan University Hospital, University of Ulsan College of Medicine, Ulsan, Korea \\ ${ }^{2}$ Department of Occupational and Environmental Medicine, Ulsan University Hospital, University of Ulsan College of Medicine, Ulsan, Korea \\ ${ }^{3}$ Division of Gastroenterology, Department of Internal Medicine, Ulsan University Hospital, University of Ulsan College of Medicine, Ulsan, Korea \\ ${ }^{4}$ Jason TG Incorporation, Seoul, Korea
}

Background: Gastroesophageal reflux disease is highly prevalent among overweight and obese individuals. This study aimed to investigate the effect of weight change on the development of erosive esophagitis (EE).

Methods: A retrospective review of medical records from a university hospital in South Korea identified 7,123 subjects who underwent routine health checkups in 2012 and 2014. We excluded participants with EE in 2012. Body mass index (BMI) changes were classified as loss, stable, mild gain, or moderate gain.

Results: Mild and moderate weight gain increased the odds of EE development (odds ratio [OR], 1.39; 95\% confidence interval [CI], 1.06-1.84 and OR, 2.80; 95\% CI, 1.87-4.21, respectively) relative to weight stability. Weight loss decreased the odds of EE development (OR, 0.58; 95\% CI, 0.38-0.90) relative to weight stability. After stratifying subjects into three groups by baseline BMI, those with mild and moderate weight gain in the obese group and moderate gain in the overweight group showed increased odds of EE development relative to members of those groups whose weights remained stable (OR, 2.08; 95\% CI, 1.29-3.36; OR, 3.92; 95\% CI, 1.99-7.73 in obese group, and OR, 3.30; 95\% CI, 1.64-6.64 in overweight group, respectively). In comparison, weight loss in the normal weight group decreased the odds of EE development relative to weight stability (OR, 0.38; 95\% CI, 0.15-0.97).

Conclusion: Weight gain was positively associated with EE development in overweight or obese individuals. Weight loss was negatively associated with EE development in normal-weight individuals.

Keywords: Esophagitis; Weight Loss; Weight Gain; Weight Change

Received: January 14, 2019, Revised: June 2, 2019, Accepted: July 14, 2019

${ }^{*}$ Corresponding Author: Tae-Heum Chung https://orcid.org/0000-0001-7994-6242

Tel: +82-52-250-7000, Fax: +82-52-250-8330, E-mail: jeongth@uuh.ulsan.kr 


\section{INTRODUCTION}

Gastroesophageal reflux disease (GERD) is a condition that develops when the reflux of stomach contents causes troublesome symptoms and/or complications. ${ }^{1)}$ Its prevalence is $10 \%-20 \%$ in the Western world and less than $5 \%$ in Asia. ${ }^{2)}$ The prevalence of GERD has been increasing since 1995, particularly in North America and East Asia. ${ }^{3)}$ The most common symptoms are heartburn, regurgitation, and dysphagia. GERD symptoms create a large burden among employers due to high absence rates and poor performance. ${ }^{4)}$

Obesity increases the risk of GERD and is independently associated with esophageal adenocarcinoma. ${ }^{5-7)}$ Although many studies have investigated the association between obesity and GERD, these studies have been cross-sectional or case-control studies or meta-analyses of cross-sectional or case-control studies. ${ }^{5-8)}$ Recently, follow-up studies evaluated the relationship between weight change and GERD, ${ }^{9-16)}$ and some of them used endoscopy for GERD. ${ }^{12-16)}$ Erosive esophagitis (EE) is a complication of GERD that can be easily detected via endoscopy and used as an objective criterion for the diagnosis of GERD. ${ }^{1)}$ However, studies exploring the development of EE stratified by weight change are rare. Moreover, because the relapse rate of healed EE is very high, evaluating the effect of weight changes on the development of EE might be invaluable to predicting whether weight change can change the relapse rate of EE. ${ }^{17}$

In this study, we assessed the effect of weight changes on the development of EE among participants who had undergone health checkups at our institution.

\section{METHODS}

\section{Participants and Procedures}

A retrospective review of the medical records of our institution identified 7,236 subjects who had undergone a routine health checkup that included esophagogastroduodenoscopy (EGD). A total of 10,723 participants underwent routine health checkups at a university hospital in South Korea in both 2012 and 2014 (Figure 1). We excluded 2,401 participants who did not undergo EGD in 2012 or 2014, 649 with EE in 2012, 63 who had previously undergone gastrectomy, and 487 with missing or incomplete data. In total, 3,600 participants were excluded. The study protocol was approved by the institutional review board of the Ulsan University Hospital (IRB approval no., UUH 2014-05-003).
Owing to the retrospective nature of the study, the requirement for informed consent was waived by the institutional review board.

\section{Data Collection}

Subjects who visited the University Hospital Health Promotion Center to undergo a health checkup were asked to complete a questionnaire about their lifestyle, medical history, educational status, and marital status. Lifestyle data included smoking status, alcohol consumption, and physical activity. Height, weight, and waist circumference (WC) were measured by trained nurses, and laboratory tests, including a serological test for Helicobacter pylori (H. pylori), were performed. EGD was performed by experienced endoscopists.

Body weight and height were measured with the subjects barefoot and wearing light indoor clothing. BMI was defined as body weight in kilograms divided by the square of height in meters. WC was measured at the midpoint between the lowest ribs and the iliac crest. Smoking was scored as "never smoked," "former smoker," or "current smoker." Alcohol consumption was calculated in grams per week and classified as " $\leq 69$," “70-140," or “ $\geq 141$ g." Physical activity was graded as "low," "moderate," or "high." ${ }^{18)}$ Educational status was scored as $\leq 9$ years (i.e., middle-school graduates), 10-12 years (i.e., high-school graduates), and $\geq 13$ years (i.e., college graduates). Marital status was classified as either married or single. $H$. pylori infection was determined on the basis of the immunoglobulin G (IgG) antibody titer for $H$. pylori, determined using the immunochemical luminescence method with DPC Immulite 2000 (DPC, Los Angeles, CA, USA). We defined positivity for $H$. pylori infection as an IgG antibody titer of $\geq 1.1 \mathrm{U} / \mathrm{mL}$.

Body mass index (BMI) change was calculated as $\{\mathrm{BMI}$ in $2014 \mathrm{(kg} /$ $\left.\mathrm{m}^{2}\right)-$ BMI in $\left.2012\left(\mathrm{~kg} / \mathrm{m}^{2}\right)\right\}$ and was classified as loss ( $\geq 0.5$ reduction), stable ( $<0.5$ change), mild gain (0.5-1.5 increase), or moderate gain ( $>1.5$ increase). On the basis of the World Health Organization's classification for BMI in the Asia-Pacific region, subjects were stratified into normal weight $\left(\mathrm{BMI}<23.0 \mathrm{~kg} / \mathrm{m}^{2}\right.$ ), overweight (BMI $23.0-24.9 \mathrm{~kg} / \mathrm{m}^{2}$ ), and obese $\left(\mathrm{BMI} \geq 25.0 \mathrm{~kg} / \mathrm{m}^{2}\right) .{ }^{19)}$

EE was defined as the presence of endoscopically detectable mucosal breaks according to the Los Angeles (LA) classification system. ${ }^{20)}$ To maximize the specificity of diagnosis of $\mathrm{EE}$ for our analyses, we considered subjects with endoscopic findings of LA-A, LA-B, LA-C, and LAD. A minimal change was not considered to be esophagitis.

\begin{tabular}{|l|l|}
3,600 Excluded \\
2,401 Not undergoing esophagogastroduodenoscopy \\
649 Having erosive esophagitis in 2012 \\
63 Undergoing gastrectomy \\
487 Having missing values
\end{tabular}

Figure 1. Selection of study subjects from participants undergoing health checkups in 2012 and 2014. 
Table 1. Baseline characteristics of subjects according to development of $E E$ at follow-up $(n=7,123)$

\begin{tabular}{|c|c|c|c|}
\hline Characteristic & $\begin{array}{c}\text { Development of } \\
\text { EE }(n=276)\end{array}$ & $\begin{array}{l}\text { No development } \\
\text { of } E E(n=6,847)\end{array}$ & P-value ${ }^{*}$ \\
\hline Age (y) & $50.8 \pm 6.8$ & $50.1 \pm 6.5$ & 0.09 \\
\hline \multicolumn{4}{|l|}{ Sex } \\
\hline Men & $260(94.2)$ & $5,633(82.3)$ & $<0.001$ \\
\hline Women & $16(5.8)$ & $1,214(17.7)$ & \\
\hline \multicolumn{4}{|c|}{ Body mass index $\left(\mathrm{kg} / \mathrm{m}^{2}\right)$} \\
\hline 2012 & $24.3 \pm 2.5$ & $23.7 \pm 2.6$ & $<0.001$ \\
\hline 2014 & $24.9 \pm 2.7$ & $24.0 \pm 2.7$ & $<0.001$ \\
\hline \multicolumn{4}{|c|}{ Waist circumference (cm ) } \\
\hline 2012 & $86.4 \pm 6.7$ & $84.4 \pm 6.9$ & $<0.001$ \\
\hline 2014 & $87.1 \pm 6.9$ & $84.4 \pm 7.0$ & $<0.001$ \\
\hline \multicolumn{4}{|l|}{ Smoking status } \\
\hline Never & 57 (20.6) & $2,531(37.0)$ & $<0.001$ \\
\hline Former & $117(42.4)$ & $2,565(37.4)$ & \\
\hline Current & $102(37.0)$ & $1,751(25.6)$ & \\
\hline \multicolumn{4}{|c|}{ Alcohol consumption (g/wk) } \\
\hline$\leq 69$ & $185(67.0)$ & $5,028(73.4)$ & 0.052 \\
\hline $70-139$ & $54(19.6)$ & $1,025(15.0)$ & \\
\hline$\geq 140$ & $37(13.4)$ & $794(11.6)$ & \\
\hline \multicolumn{4}{|l|}{ Physical activity } \\
\hline Low & $184(66.7)$ & 4,652 (67.9) & 0.86 \\
\hline Moderate & $63(22.8)$ & $1,537(22.5)$ & \\
\hline High & 29 (10.5) & $658(9.6)$ & \\
\hline \multicolumn{4}{|l|}{ Education (y) } \\
\hline$\leq 9$ & 45 (16.3) & $1,079(15.8)$ & 0.84 \\
\hline $10-12$ & $125(45.3)$ & $3,017(44.0)$ & \\
\hline$\geq 13$ & $106(38.4)$ & $2,751(40.2)$ & \\
\hline \multicolumn{4}{|l|}{ Marital status } \\
\hline Single & $11(4.0)$ & $270(3.9)$ & 0.972 \\
\hline Married & $265(96.0)$ & 6,577 (96.1) & \\
\hline \multicolumn{4}{|l|}{ Helicobacter pylori } \\
\hline Negative & $150(54.4)$ & 2,321 (33.9) & $<0.001$ \\
\hline Positive & $126(45.6)$ & $4,526(66.1)$ & \\
\hline
\end{tabular}

Values are presented as mean \pm standard deviation or number (\%).

$\mathrm{EE}$, erosive esophagitis.

*By Student t-test for comparison of continuous variables, and chi-square test for comparison of categorical variables.

\section{Statistical Analyses}

We tabulated the general characteristics of subjects according to the development of EE and compared the means and distributions of the variables. Student t-test was used for continuous variables, and the chi-square test was used for categorical variables. We calculated the odds ratios (ORs) and 95\% confidence intervals (CIs) for the development of EE by BMI change over 2 years. A multivariate logistic regression model was used and adjusted for age, sex, baseline BMI, smoking status, alcohol consumption, physical activity, education, marital status, and $H$. pylori infection. All statistical analyses were performed using STATA ver. 13.1 software (Stata Corp., College Station, TX, USA).

\section{RESULTS}

Among the 7,123 subjects who did not have EE in 2012, 276 (3.9\%)
Table 2. OR with $95 \% \mathrm{Cl}$ for the development of EE by change in BMI

\begin{tabular}{lccc}
\hline Characteristic & EE/all (\%) & Crude OR $(95 \% \mathrm{Cl})^{\star}$ & $\begin{array}{c}\text { Adjusted OR } \\
(95 \% \mathrm{Cl})^{*,+}\end{array}$ \\
\hline $\begin{array}{l}\text { Change in BMI } \\
\left(\mathrm{kg} / \mathrm{m}^{2}\right)\end{array}$ & & & \\
Loss & $27 / 1,341(2.0)$ & $0.59(0.38-0.90)$ & $0.58(0.38-0.90)$ \\
Stable & $99 / 2,922(3.4)$ & $1.00($ Reference) & 1.00 (Reference) \\
$\quad$ Mild gain & $114 / 2,448(4.7)$ & $1.39(1.06-1.83)$ & $1.39(1.06-1.84)$ \\
$\quad$ Moderate gain & $36 / 412(8.7)$ & $2.73(1.84-4.06)$ & $2.80(1.87-4.21)$ \\
P-value for trend $^{\ddagger}$ & & $<0.001$ & $<0.001$ \\
\hline
\end{tabular}

OR, odds ratio; $\mathrm{Cl}$, confidence interval; $\mathrm{EE}$, erosive esophagitis; $\mathrm{BMI}$, body mass index.

*Using logistic regression analysis. ${ }^{\dagger}$ Adjusted for age, sex, baseline BMI, smoking status, alcohol consumption, physical activity, education, marital status, and Helicobacter pylori. *By Wald test for linear trend.

Table 3. Odds ratio with $95 \%$ confidence interval ${ }^{*, \dagger}$ for the development of erosive esophagitis by change in BMI in three groups stratified by baseline BMI

\begin{tabular}{lccc}
\hline \multicolumn{1}{c}{ Characteristic } & $\begin{array}{c}\mathrm{BMl}<23.0 \\
(\mathrm{n}=2,735)\end{array}$ & $\begin{array}{c}\mathrm{BMl} 23.0-24.9 \\
(\mathrm{n}=2,196)\end{array}$ & $\begin{array}{c}\mathrm{BMI} \geq 25.0 \\
(\mathrm{n}=2,192)\end{array}$ \\
\hline $\begin{array}{l}\text { Change in BMI } \\
\left(\mathrm{kg} / \mathrm{m}^{2}\right)\end{array}$ & & & \\
Loss & $0.38(0.15-0.97)$ & $0.90(0.46-1.78)$ & $0.57(0.27-1.19)$ \\
Stable & $1.00($ Reference) & 1.00 (Reference) & 1.00 (Reference) \\
$\quad$ Mild gain & $1.00(0.62-1.63)$ & $1.30(0.78-2.15)$ & $2.08(1.29-3.36)$ \\
$\quad$ Moderate gain & $1.69(0.76-3.78)$ & $3.30(1.64-6.64)$ & $3.92(1.99-7.73)$ \\
P-value for trend $^{\ddagger}$ & $<0.001$ & $<0.001$ & $<0.001$
\end{tabular}

Values are presented as odds ratio ( $95 \%$ confidence interval).

BMl, body mass index $\left(\mathrm{kg} / \mathrm{m}^{2}\right)$.

${ }^{*}$ Using logistic regression analysis. ${ }^{\dagger}$ Adjusted for age, sex, baseline BMI, smoking status, alcohol consumption, physical activity, education, marital status, and Helicobacter pylori. `By Wald test for linear trend.

were newly diagnosed with EE in 2014. Subject characteristics according to the development of EE are shown in Table 1. The subjects who were newly diagnosed with EE were more likely to be male, have a higher BMI and higher WC, be a current smoker, and exhibit higher alcohol consumption; further, they were less likely to have $H$. pylori infection.

The development of EE according to the change in BMI is shown in Table 2. Weight change was associated with the development of EE in a dose-dependent manner (P-value for trend $<0.001$ ). Weight loss decreased the odds of EE development (OR, 0.58; 95\% CI, 0.38-0.90) compared with weight stability. In comparison, mild and moderate weight gain increased the odds of EE development (OR, 1.39; 95\% CI, 1.06-1.84 and OR, 2.80; 95\% CI, 1.87-4.21, respectively) compared with weight stability.

Analysis of the three groups stratified by baseline BMI showed a similar pattern. The development of EE according to the change in BMI in each group is shown in Table 3 and Figure 2. Weight gain was associated with the development of $\mathrm{EE}$ in a dose-dependent manner in all three groups (P-value for trend $<0.001$ ). Weight loss decreased the odds of EE development in the normal weight group (BMI $<23.0$ $\mathrm{kg} / \mathrm{m}^{2}$ ) (OR, 0.38; 95\% CI, 0.15-0.97) compared with weight stability. Moderate weight gain in the overweight group (BMI $23.0-24.9 \mathrm{~kg} / \mathrm{m}^{2}$ ) 
A

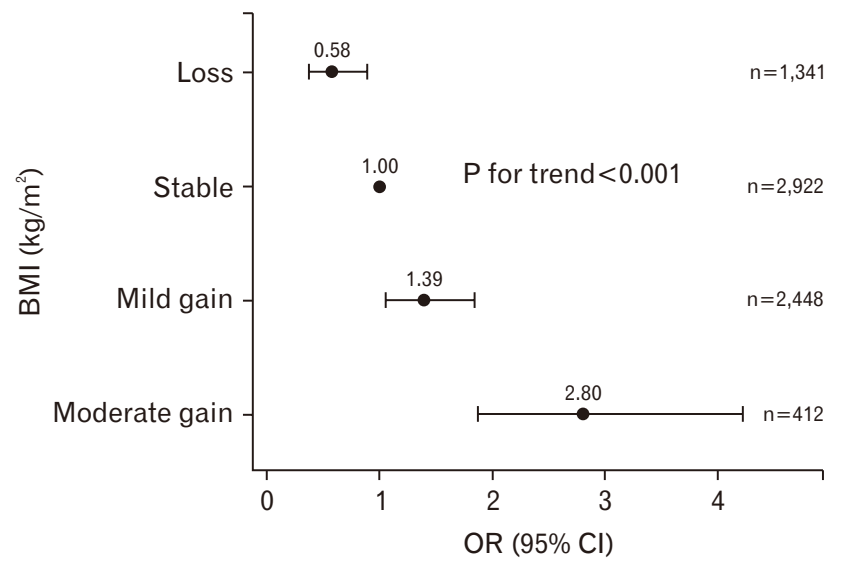

C

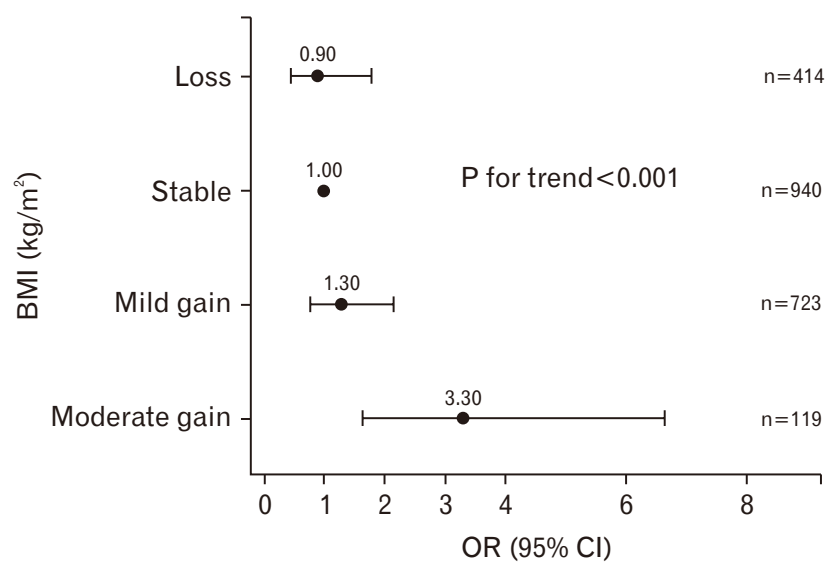

B

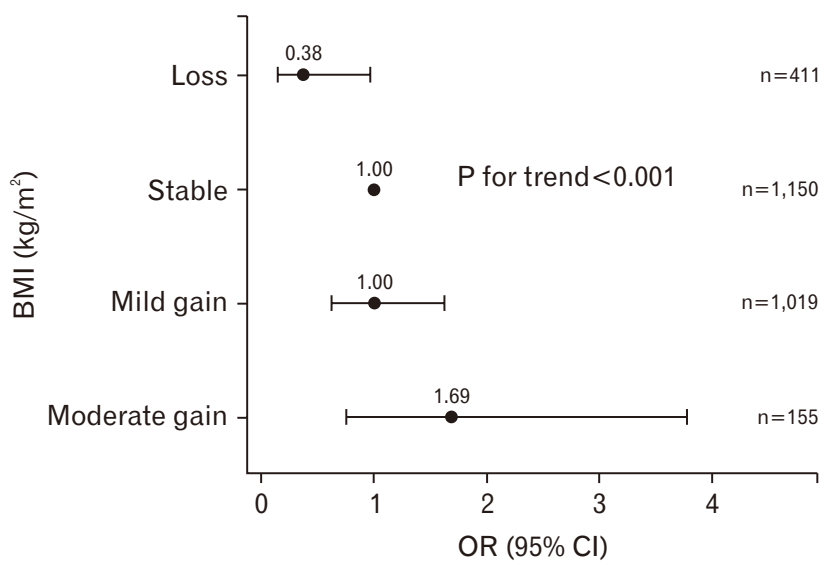

D

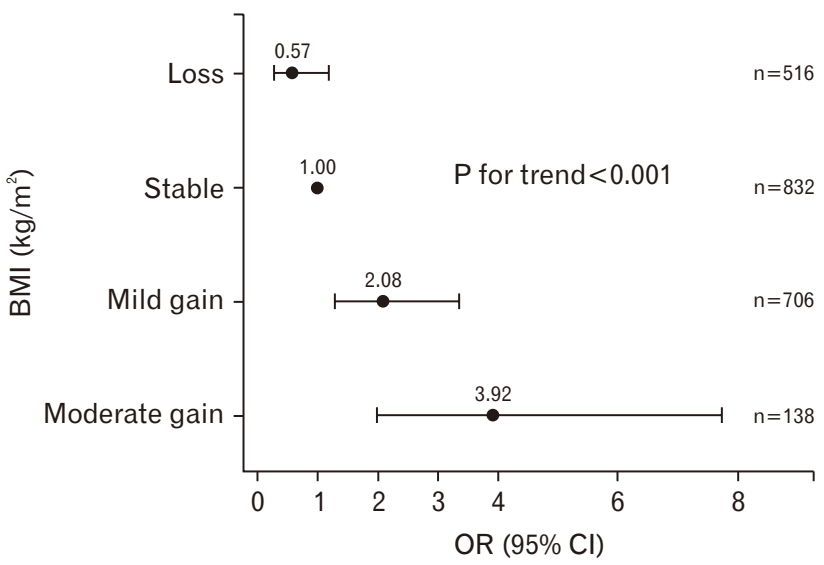

Figure 2. ORs with $95 \%$ Cls for development of erosive esophagitis by change in BMl adjusted for age, sex, baseline BMl, smoking status, alcohol consumption, physical activity, education, marital status, and Helicobacter pylori infection; stratified by weight at baseline: (A) all subjects; (B) subjects with BMl $<23.0 \mathrm{~kg} / \mathrm{m}^{2} ;(\mathrm{C})$ subjects with BMI 23.0-24.9 kg/m²; (D) subjects with $\mathrm{BMl} \geq 25.0 \mathrm{~kg} / \mathrm{m}^{2}$. BMl, body mass index; OR, odds ratio; $\mathrm{Cl}$, confidence interval.

increased the odds of EE development (OR, 3.30; 95\% CI, 1.64-6.64) compared with weight stability. Mild and moderate weight gains in the obese group (BMI $\geq 25.0 \mathrm{~kg} / \mathrm{m}^{2}$ ) increased the odds of EE development compared with weight stability (OR, 2.08; 95\% CI, 1.29-3.36 and OR, 3.92; 95\% CI, 1.99-7.73, respectively).

\section{DISCUSSION}

Weight gain was positively associated with the development of EE in a dose-dependent manner, while weight loss was negatively associated with the development of EE. After stratifying subjects into three groups by baseline BMI, mild and moderate weight gain in the obese group and mild weight gain in the overweight group increased the odds of EE development compared with weight stability. In comparison, weight loss in the normal weight group decreased the odds of EE development compared with weight stability.

In our study, 3.9\% of patients were newly diagnosed with EE in 2014. The results are consistent with those from a Korean study that reported that $4.1 \%$ of their subjects were newly diagnosed with EE.14 Another
Korean study showed that $5.3 \%$ of subjects were diagnosed with EE in 2 years, but the subjects were only males; ${ }^{15)}$ male sex has been reported as one of the risk factors of EE. ${ }^{21)}$

Although the ways in which obesity contributes to GERD are not completely understood, some studies have suggested potential mechanisms. An observational study noted a significant correlation of BMI and WC with intra-gastric pressure and the gastro-esophageal pressure gradient. ${ }^{22)} \mathrm{A}$ cross-sectional study of consecutive patients undergoing 24-hour pH-measurements showed that obesity also increases the risk of GERD by increasing esophageal acid exposure. ${ }^{23)}$

A few studies have also investigated the association between weight change and development of EE. ${ }^{12,14-16)}$ Nam et al., ${ }^{15)}$ who also used data from Korean health screening programs, showed that weight gain is associated with new occurrences of $\mathrm{EE}$, and their results are similar to ours. However, their study was done only on males and did not find an association between weight loss and EE. Koo et al. ${ }^{14)}$ suggested that abdominal obesity is a risk factor for the development of EE in Koreans, but they did not find an association between weight change and EE. Working from the National Health and Nutrition Examination Sur- 
vey, a population-based sample in Americans, Ruhl et al. ${ }^{16)}$ found that being overweight increases the risk of hospitalization for GERD. Bang and Park ${ }^{12)}$ have investigated weight loss as a non-pharmacologic strategy for EE, and they reported that substantial weight loss is associated with EE resolution. Although EE resolution is a different outcome from our outcome of EE development, the finding that weight loss has a positive effect on EE was supported by both studies.

Moreover, the results of the analyses that we stratified by baseline BMI suggest that weight gain in overweight or obese groups may be more likely to support the development of EE than in the normal weight group. Therefore, overweight or obese individuals should be more careful than normal-weight individuals not to gain weight in order to prevent the development of EE. To our knowledge, no prior studies compare the effect of an increase in BMI on EE development in groups stratified by baseline BMI. Hallan et al. ${ }^{9)}$ assessed the risk of new-onset gastroesophageal reflux symptoms by changes in BMI. They found that a BMI increase of $>1.5-3.5$ or $>3.5$ units in the preobese group (BMI $25.0-29.9 \mathrm{~kg} / \mathrm{m}^{2}$ ) and a BMI increase of $>3.5$ units in the normal weight group (BMI $\left.<25.0 \mathrm{~kg} / \mathrm{m}^{2}\right)$ were associated with newonset gastroesophageal reflux symptoms.

Conversely, weight loss decreased the odds of EE development only in the normal weight group, but not in the overweight and obese groups. This suggests that weight loss in overweight or obese groups may be less likely to protect against the development of EE than in normal weight groups, so overweight or obese individuals may need to lose more weight to protect against the development of EE than normal-weight individuals do. However, our study was limited to evaluating the protective effect of substantial weight loss on the development of EE, because the mean BMI change in the weight loss group was about 1 unit.

The present study has several strengths. First, this study is the first trial to report the effect of weight change on the development of EE by baseline BMI. Second, the results may be applied not only to the development of new-onset EE, but also to relapses of EE. Although we were not able to differentiate whether the developed EE was new-onset or relapse, many incidences of EE were likely to be a relapse owing to the fact that the relapse rate of healed EE without maintenance therapy is approximately $70 \%$ within 6 months and up to $90 \%$ within 1 year. ${ }^{17)}$

This study has some limitations as well. First, the subjects were relatively healthy because most of them had undergone a regular health checkup. Therefore, selection bias may have prevented accurate representation of the full Korean population. Second, we did not investigate the history of reflux-inducing factors, including supine positions after meals, meals before bedtime, and dietary factors such as fat, chocolate, and caffeine intake. These dietary factors can confound the association between BMI change and EE. Third, we did not adjust for antireflux medications. Anti-reflux medications might dilute the effect of weight gain on EE, bringing the odds ratios closer to null. Fourth, interoperator variations of EGD in the assessment of esophagitis could occur. To minimize this, the Los angeles classification system was used.
This classification system is most thoroughly evaluated for esophagitis and is widely used. Finally, we were not able to classify the weight loss group into sub-groups because the number of subjects who lost weight was not large enough to be classified further. Hence, the group was limited to evaluating the protective effect of weight loss on the development of EE in detail.

In this retrospective study, weight gain was positively associated with the development of EE in overweight or obese individuals. Weight loss was negatively associated with the development of EE in normalweight individuals. Overweight or obese individuals should be more careful than normal-weight individuals not to gain weight to prevent the development of EE. Additionally, physicians should pay attention to weight change to prevent EE. Further studies that take the history of reflux-inducing habits into consideration and increase the sample size of the weight loss group are required to confirm the effect of weight change on the development of EE.

\section{CONFLICT OF INTEREST}

No potential conflict of interest relevant to this article was reported.

\section{FUNDING}

This work was funded by Ulsan University Hospital (Biomedical Research Center Promotion Fund).

\section{ORCID}

Tae-Heum Chung: https://orcid.org/0000-0001-7994-6242

Jiho Lee: https://orcid.org/0000-0001-8027-835X

In-Du Jeong: https://orcid.org/0000-0002-6212-1460

Kun-Chul Lee: https://orcid.org/0000-0002-7636-8114

\section{REFERENCES}

1. Vakil N, van Zanten SV, Kahrilas P, Dent J, Jones R; Global Consensus Group. The Montreal definition and classification of gastroesophageal reflux disease: a global evidence-based consensus. Am J Gastroenterol 2006;101:1900-20.

2. Dent J, El-Serag HB, Wallander MA, Johansson S. Epidemiology of gastro-oesophageal reflux disease: a systematic review. Gut 2005;54: 710-7.

3. El-Serag HB, Sweet S, Winchester CC, Dent J. Update on the epidemiology of gastro-oesophageal reflux disease: a systematic review. Gut 2014;63:871-80.

4. Locke GR 3rd, Talley NJ, Fett SL, Zinsmeister AR, Melton LJ 3rd. Prevalence and clinical spectrum of gastroesophageal reflux: a populationbased study in Olmsted County, Minnesota. Gastroenterology 1997;112:1448-56.

5. Nilsson M, Johnsen R, Ye W, Hveem K, Lagergren J. Obesity and estrogen as risk factors for gastroesophageal reflux symptoms. JAMA 2003;290:66-72. 
6. Hampel H, Abraham NS, El-Serag HB. Meta-analysis: obesity and the risk for gastroesophageal reflux disease and its complications. Ann Intern Med 2005;143:199-211.

7. Corley DA, Kubo A. Body mass index and gastroesophageal reflux disease: a systematic review and meta-analysis. Am J Gastroenterol 2006; 101:2619-28.

8. Cai N, Ji GZ, Fan ZN, Wu YF, Zhang FM, Zhao ZF, et al. Association between body mass index and erosive esophagitis: a meta-analysis. World J Gastroenterol 2012;18:2545-53.

9. Hallan A, Bomme M, Hveem K, Moller-Hansen J, Ness-Jensen E. Risk factors on the development of new-onset gastroesophageal reflux symptoms: a population-based prospective cohort study: the HUNT study. Am J Gastroenterol 2015;110:393-400.

10. Ness-Jensen E, Lindam A, Lagergren J, Hveem K. Weight loss and reduction in gastroesophageal reflux. A prospective population-based cohort study: the HUNT study. Am J Gastroenterol 2013;108:376-82.

11. Jacobson BC, Somers SC, Fuchs CS, Kelly CP, Camargo CA Jr. Bodymass index and symptoms of gastroesophageal reflux in women. $\mathrm{N}$ Engl J Med 2006;354:2340-8.

12. Bang KB, Park JH. Weight loss as a nonpharmacologic strategy for erosive esophagitis: a 5-year follow-up study. Gut Liver 2018;12:633-40.

13. Park SK, Lee T, Yang HJ, Park JH, Sohn CI, Ryu S, et al. Weight loss and waist reduction is associated with improvement in gastroesophageal disease reflux symptoms: a longitudinal study of 15295 subjects undergoing health checkups. Neurogastroenterol Motil 2017;29.

14. Koo JS, Lee SW, Park SM, Jung SW, Yim HJ, Park JJ, et al. Abdominal obesity as a risk factor for the development of erosive esophagitis in subjects with a normal esophago-gastric junction. Gut Liver 2009;3: 276-84.
15. Nam SY, Choi IJ, Nam BH, Park KW, Kim CG. Obesity and weight gain as risk factors for erosive oesophagitis in men. Aliment Pharmacol Ther 2009;29:1042-52.

16. Ruhl CE, Everhart JE. Overweight, but not high dietary fat intake, increases risk of gastroesophageal reflux disease hospitalization: the NHANES I Epidemiologic Followup Study: first National Health and Nutrition Examination Survey. Ann Epidemiol 1999;9:424-35.

17. Freston JW, Jackson RL, Huang B, Ballard ED 2nd. Lansoprazole for maintenance of remission of erosive oesophagitis. Drugs 2002;62: 1173-84.

18. Chun MY. Validity and reliability of Korean version of international physical activity questionnaire short form in the elderly. Korean J Fam Med 2012;33:144-51.

19. World Health Organization Regional Office for the Western Pacific; International Association for the Study of Obesity; International Obesity Task Force. The Asia-Pacific perspective: redefining obesity and its treatment. Sydney: Health Communications Australia; 2000.

20. Lundell LR, Dent J, Bennett JR, Blum AL, Armstrong D, Galmiche JP, et al. Endoscopic assessment of oesophagitis: clinical and functional correlates and further validation of the Los Angeles classification. Gut 1999;45:172-80.

21. Cook MB, Wild CP, Forman D. A systematic review and meta-analysis of the sex ratio for Barrett's esophagus, erosive reflux disease, and nonerosive reflux disease. Am J Epidemiol 2005;162:1050-61.

22. Pandolfino JE, El-Serag HB, Zhang Q, Shah N, Ghosh SK, Kahrilas PJ. Obesity: a challenge to esophagogastric junction integrity. Gastroenterology 2006;130:639-49.

23. El-Serag HB, Ergun GA, Pandolfino J, Fitzgerald S, Tran T, Kramer JR. Obesity increases oesophageal acid exposure. Gut 2007;56:749-55. 